九州大学学術情報リポジトリ

Kyushu University Institutional Repository

Sequential Fractionation of Copper, Nickel, Lead, and Zinc in Agricultural Soils and RiverSediment in Tuliem and Thanhtri Districts of Hano i City, Vietnam

Tra, Ho Thi Lam

Laboratory of Soils, Faculty of Agricullure, Kyushu University

Egashira, Kazuhiko

Laboratory of Soils, Faculty of Agricullure, Kyushu University

https://doi.org/10.5109/24297

出版情報：九州大学大学院農学研究院紀要. 43 (3/4)，pp.499-508，1999-02. Kyushu University バージョン：

権利関係 : 
J. Fac. Agr., Kyushu Univ., 43 (3•4), 499-508 (1999)

\title{
Sequential Fractionation of Copper, Nickel, Lead, and Zine in Agricultural Soils and River-Sediment in Tuliem and Thanhtri Districts of Hanoi City, Vietnam
}

\author{
Ho Thi Lam Tra and Kazuhiko Egashira
}

\author{
Laboratory of Soils, Faculty of Agriculture, Kyushu Lniversily, Fukuoka 812-8581, Japan \\ (Received October 1, 1998 and accepted Nonember 6, 1998)
}

\begin{abstract}
Sequential fractionation was applied to partition heavy metals in the agricultural soils and river-scdiment taken from Tuliem and Thanhtri districts of Hanoi city. Although there was observed a considerable variation among the heavy metals in the proportion of various fractions, $\mathrm{Pb}$ showed the similar percentage of each fraction between the agricultural soils and river-sediment, and the Fe-Mn oxides and residual fractions overwhelmingly dominated over the other three fractions. In the speciation of $\mathrm{Cu}$, one agricultural soil which was supposed to be polluted with $\mathrm{Cu}$ showed the relatively high percentage of the $\mathrm{Fe}-\mathrm{Mn}$ oxides fraction. In the river-sediment $\mathrm{Cu}$ was occupied with the orgarlic fraction in around $70 \%$. In $\mathrm{Ni}$ and $\mathrm{Zn}$, the river-sediment showed the high proportion of the exchangeable and carbonates fractions. The sum of both fractions was about 25 and $30 \%$ for $\mathrm{Ni}$ and $\mathrm{Zn}$, respectively, while it was quite low in the agricultural soils. Mobility of heavy metals in the river-sediment was estimated to be in the sequence of $\mathrm{Ni}, \mathrm{Zn}>\mathrm{Cu}>\mathrm{Pb}$. Based on its higher mobility along with the high total content in the river-sediment, the first priority should be placed on $\mathrm{Zn}$ from the viewpoint of the control of heavy metal pollution.
\end{abstract}

\section{INTRODUCTION}

In recent years increased industrialization and population growth have led to progressively increasing fluxes of many heavy metals to soil and river in Hanoi city, Vietnam. In the previous paper (Ho and Egashira, 1999), the authors investigated the heavy metal status of the agricultural soils and river-sediment taken from Tuliem and Thanhtri districts of Hanoi city. Accumulation of several kinds of heavy metals was noticed in the river-sediment of the Kimnguu River, in contrast to the agricultural soils being in the normal range of the heavy metals examined, except for one upland soil cultivated for vegetables throughout the year in which $\mathrm{Cu}$ pollution was suspposed.

In most studies dealing with heavy metals, only total contents have been reported, to give an information concerning possible enrichment in soils. However, total content of heavy metals is not enough to estimate toxicity and mobility of them in soils and sediments. A knowledge of distribution of heavy metals among various forms or chemical forms of heavy metals associated with particulates is essential for estimating biological availability or physicochemical reactivity of heavy metals in soils and sediments. Heavy metals may be complexed with organic compounds, adsorbed or occluded in carbonates or oxide minerals or in the structure of primary and secondary minerals (Hickey and Kittrick, 1984).

The objective of the present study was to determine the chemical partition of $\mathrm{Cu}, \mathrm{Ni}$, $\mathrm{Pb}$, and $\mathrm{Zn}$ in the river-sediment in comparison with agricultural soils, both taken from 
Tuliem and Thanhtri districts of Hanoi city. Three soils and one river-sediment were selected for this purpose from the samples used in the previous study (Ho and Egashira, 1999). The samples were subjected to sequential fractionation and the heavy metals were partitioned into five operationally defined fractions: exchangeable, bound to carbonates, bound to iron and manganese oxides, bound to organic matter, and residual.

\section{MATERIALS AND METHODS}

\section{Location and samples}

Samples selected for the present study are briefly described in Table 1. Sampling sites of soils and river-sediment and the river system in Tuliem and Thanhtri districts of Hanoi city were indicated in the previous paper (Ho and Egashira, 1999). Three soil samples are as follows: sample No.1 is supposed to be polluted with $\mathrm{Cu}$; samples No.4 and No.6 are in the normal range of heavy metals and were selected as a representative of agricultural soils of Tuliem and Thanhtri districts, respectively. The river-sediment is a sample from the Kimnguu River and was found to be highly accumulated with different. heavy metals.

\section{Sequential fractionation of heavy metals}

Determination of speciation or distribution of $\mathrm{Cu}, \mathrm{Ni}, \mathrm{Pb}$, and $\mathrm{Zn}$ in soil and river-sediment was made by the Tessier et al. (1979) sequential chemical extraction scheme (Fig. 1). One gram of sample was used and extractions were carried out directly in 50-mL polypropylene Nalgene centrifuge tubes to minimize losses of solid material. Residues were separated from the supernatant by 30 min centrifugation at $10,000 \mathrm{~min}^{-1}$ speed. The residue was washed with $8 \mathrm{~mL}$ of water followed by hand shaking and then followed by $30 \mathrm{~min}$ centrifugation before the next extraction. Metal content of the five fractions in the filtered solution was determined by atomic absorption spectrometry. Determination was made in duplicate and the relative deviation of the duplicate values was usually less than $5 \%$. Due to no contamination of $\mathrm{Mn}$, low confent of total $\mathrm{Cd}$ in agricultural soils, and a close similarity of $\mathrm{Cr}$ with $\mathrm{Ni}$ (Ho and Egashira: 1999), these three metals were not considered in the present study.

Table 1. Bricf description of agricultural soils and river-sediment used in the study.

\begin{tabular}{|c|c|c|c|c|c|}
\hline \multirow{2}{*}{$\begin{array}{l}\text { Sample } \\
\text { No. }\end{array}$} & \multicolumn{2}{|c|}{ Location } & \multirow{2}{*}{$\begin{array}{l}\text { Land use } \\
\text { (crop) }\end{array}$} & \multirow{2}{*}{$\begin{array}{l}\text { Relative land height } \\
\text { in the region }\end{array}$} & \multirow{2}{*}{$\begin{array}{c}\text { Soil classification by } \\
\text { rAO/UNESO }\end{array}$} \\
\hline & District & Commune & & & \\
\hline 1 & Tuliem & Taytuu & $\begin{array}{c}\text { Upland } \\
\text { (vegetables) }\end{array}$ & High & $\begin{array}{c}\text { Orthi-Umbri-Eutrie } \\
\text { Fluvisols }\end{array}$ \\
\hline 4 & & Yenhoa & $\begin{array}{c}\text { Paddy } \\
\text { (rice-rice) }\end{array}$ & Lowest (marshy) & $\begin{array}{c}\text { Epi-Stagni-Eutric } \\
\text { Gleysols }\end{array}$ \\
\hline 6 & Thanhtri & Thanhlict & $\begin{array}{c}\text { Paddy } \\
\text { (rice-rice) }\end{array}$ & Middle & $\begin{array}{c}\text { Orthi-Plinthi-Eutric } \\
\text { Fluvisols }\end{array}$ \\
\hline 10 & & Tranphu & - & River bed & - \\
\hline
\end{tabular}




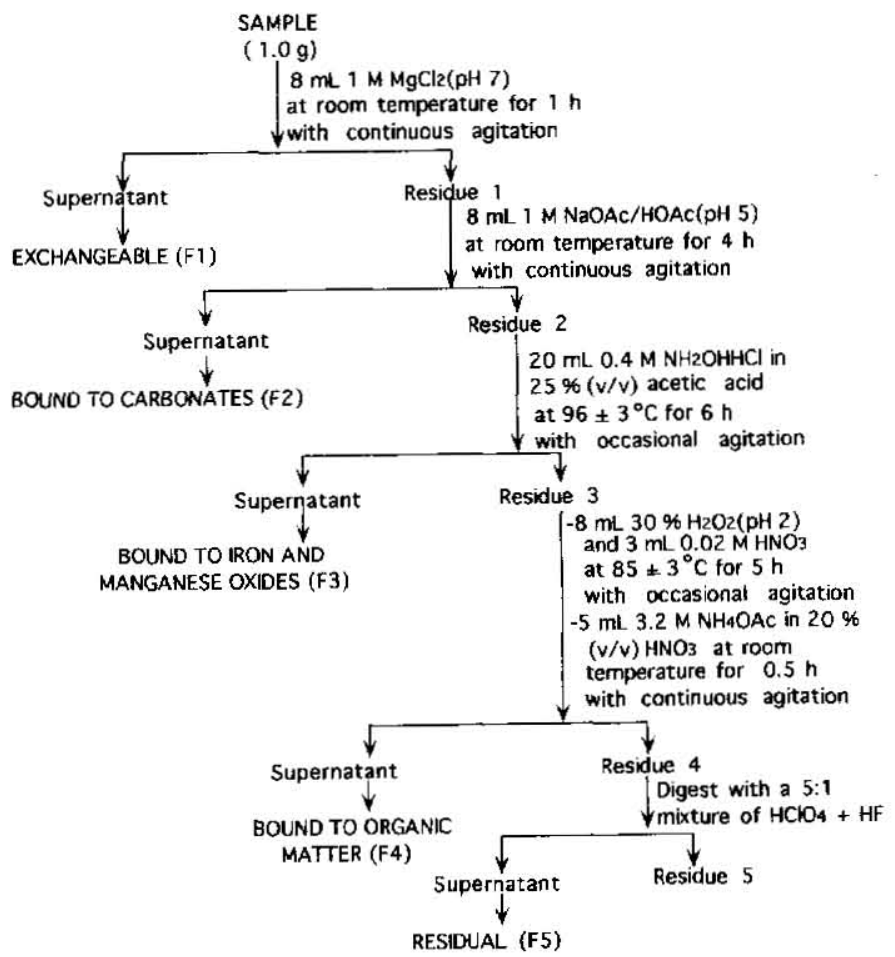

Fig. 1. Sequential fractionation scheme for the speciation of heavy metals.

\section{RESULTS}

\section{Total heavy metal contents}

Contents of total $\mathrm{Cu}, \mathrm{Ni}, \mathrm{Pb}$, and $\mathrm{Zn}$ for the agricultural soils and river-sediment are reproduced in Table 2 (Ho and Egashira, 1999). Contents of the total heavy metals were regarded to be in the normal range for the agricultural soils, except for $\mathrm{Cu}$ in sample No.1. In contrast, the river-sediment of the Kimnguu River flowing through the area contained large amounts of total $\mathrm{Zn}, \mathrm{Cu}, \mathrm{Pb}$, and $\mathrm{Ni}$, and order of the content was $\mathrm{Zn}>\mathrm{Cu}>\mathrm{Pb}>\mathrm{Ni}$.

\section{Speciation of heavy metals}

Contents of sequentially fractionated heavy metals are given in Table 3. Total of the contents of five fractions is expected to be equal to the total content listed in Table 2. However, the former amounted only to $62-82,78-97,72-89$, and $62-83 \%$ of the latter for $\mathrm{Cu}, \mathrm{Ni}, \mathrm{Pb}$, and $\mathrm{Zn}$, respectively. A possible reason to be below $100 \%$ is underestimation of the content of the residual fraction due to the difference between procedures used for 
Table 2. Contents of total heavy metals in agricultural soils and river-sediment ( $m g \mathrm{~kg}^{\prime}$ ).

\begin{tabular}{ccrrc}
\hline $\begin{array}{c}\text { Sample } \\
\text { No }\end{array}$ & Cu & $\mathrm{Ni}$ & $\mathrm{Pb}$ & $\mathrm{Zn}$ \\
\hline 1 & 73.2 & 33.6 & 31.9 & 114.5 \\
4 & 50.0 & 45.6 & 45.1 & 116.9 \\
6 & 43.0 & 66.0 & 45.3 & 137.2 \\
10 & 258 & 145.5 & 157.5 & 1040 \\
\hline
\end{tabular}

Table 3. Contents of sequentially fractionated heavy metals in agricultural soils and river-sedimlent (mg kg :).

\begin{tabular}{|c|c|c|c|c|c|}
\hline $\begin{array}{c}\text { Sample } \\
\text { No. }\end{array}$ & Fraction & $\mathrm{Cu}$ & $\mathrm{Ni}$ & $\mathrm{Pb}$ & $\mathrm{Zn}$ \\
\hline \multirow{6}{*}{1} & Exchangaeble & NT) & 1.0 & 1.0 & ND \\
\hline & Bound to carbonates & 1.4 & 1.3 & 1.0 & 4.5 \\
\hline & Bound to Fe-Mn oxides & 25.1 & 11.2 & 13.3 & 42.5 \\
\hline & Bound to organic matter & 8.9 & 4.6 & 2.9 & 4.0 \\
\hline & Residual & 18.8 & 14.5 & 10.2 & 36.3 \\
\hline & & $(37.8)$ & $(15.5)$ & $(13.7)$ & $(63.5)$ \\
\hline \multirow{6}{*}{4} & Exchangaeble & ND & 0.9 & 1.3 & $\mathrm{ND}$ \\
\hline & Bound to carbonates & 0.2 & 1.2 & 1.9 & 0.4 \\
\hline & Bound to $\mathrm{Fe}-\mathrm{Mn}$ oxides & 9.3 & 10.6 & 19.4 & 27.2 \\
\hline & Bound to organic matter & 8.8 & 4.0 & 2.9 & 4.5 \\
\hline & Residual & 17.9 & 20.8 & 12.7 & 51.7 \\
\hline & & $(31.7)$ & $(28.9)$ & $(19.6)$ & $(84.8)$ \\
\hline \multirow{6}{*}{6} & Exchangaeble & ND) & 1.4 & 0.6 & 0.1 \\
\hline & Bound to carbonates & ND & 1.5 & 1.3 & 4.1 \\
\hline & Round to Fe-Mr oxides & 4.4 & 16.4 & 19.2 & 27.3 \\
\hline & Bound to organic matter & 4.4 & 5.9 & 3.1 & 6.1 \\
\hline & Residual & 17.9 & 26.3 & 9.9 & 47.3 \\
\hline & & $(34.2)$ & $(40.8)$ & (21.1) & $(99.6)$ \\
\hline \multirow{6}{*}{10} & Exchangaeble & 6.2 & 11.1 & 0.7 & 46.6 \\
\hline & Bound to carbonates & 9.1 & 21.0 & 3.7 & 249 \\
\hline & Bound to Fe-Mn oxides & 15.2 & 65.6 & 72.2 & 485 \\
\hline & Bound to organic matter & 164.6 & 13.0 & 6.5 & 41.6 \\
\hline & Residual & 16.6 & 12.8 & 29.9 & 36.2 \\
\hline & & $(63)$ & $(34.8)$ & $(74.4)$ & (218) \\
\hline
\end{tabular}

ND: not detected.

The values in the parenthesis are the content of the residual fraction calculated as the difference between the total content listed in Table 2 and the total of the contents of four fractions excluding the residual fraction. 

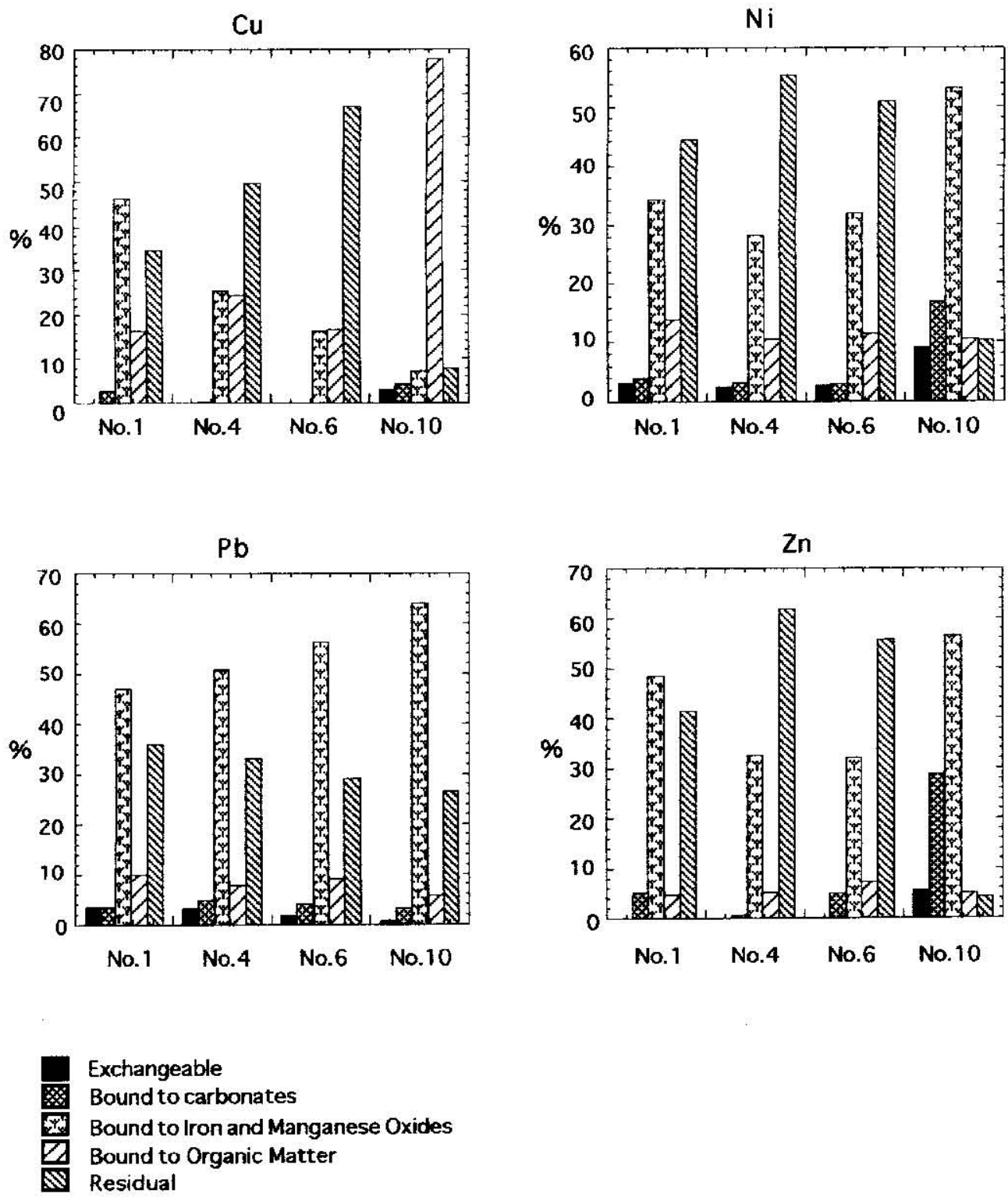

Fig. 2. Percentages of $\mathrm{Cu}, \mathrm{Ni}, \mathrm{Pb}$, and $\mathrm{Zn}$ associated with each of five sequential fractions for agricultural soils and river-scdiment, in which the content of the residual fraction measured by the sequential fractionation illustrated in Fig. 1 was used as such. 

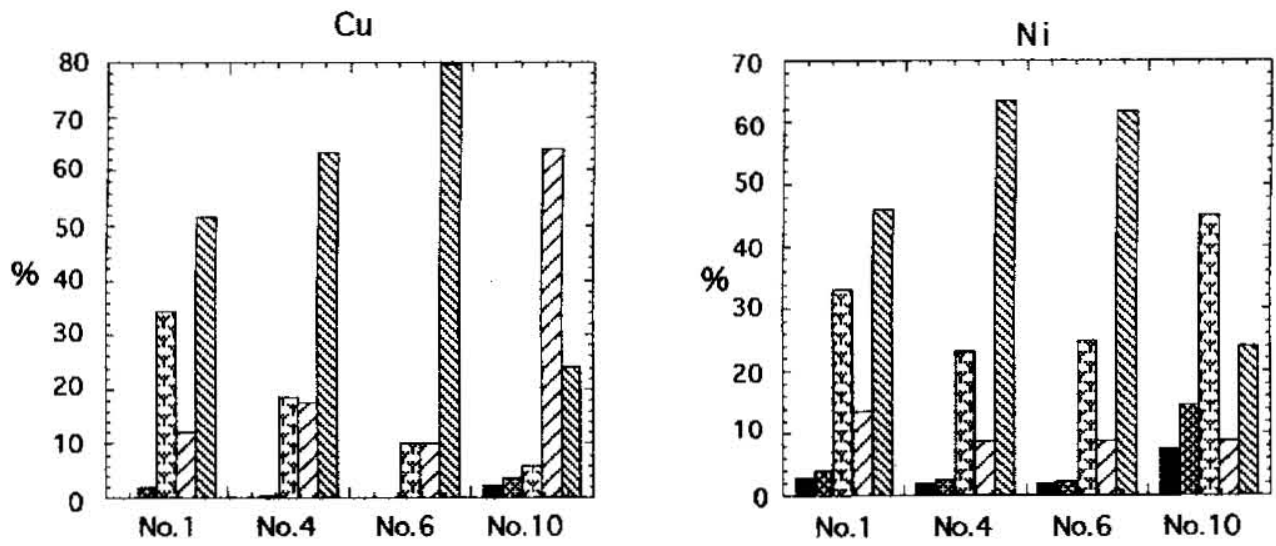

$\mathrm{Pb}$
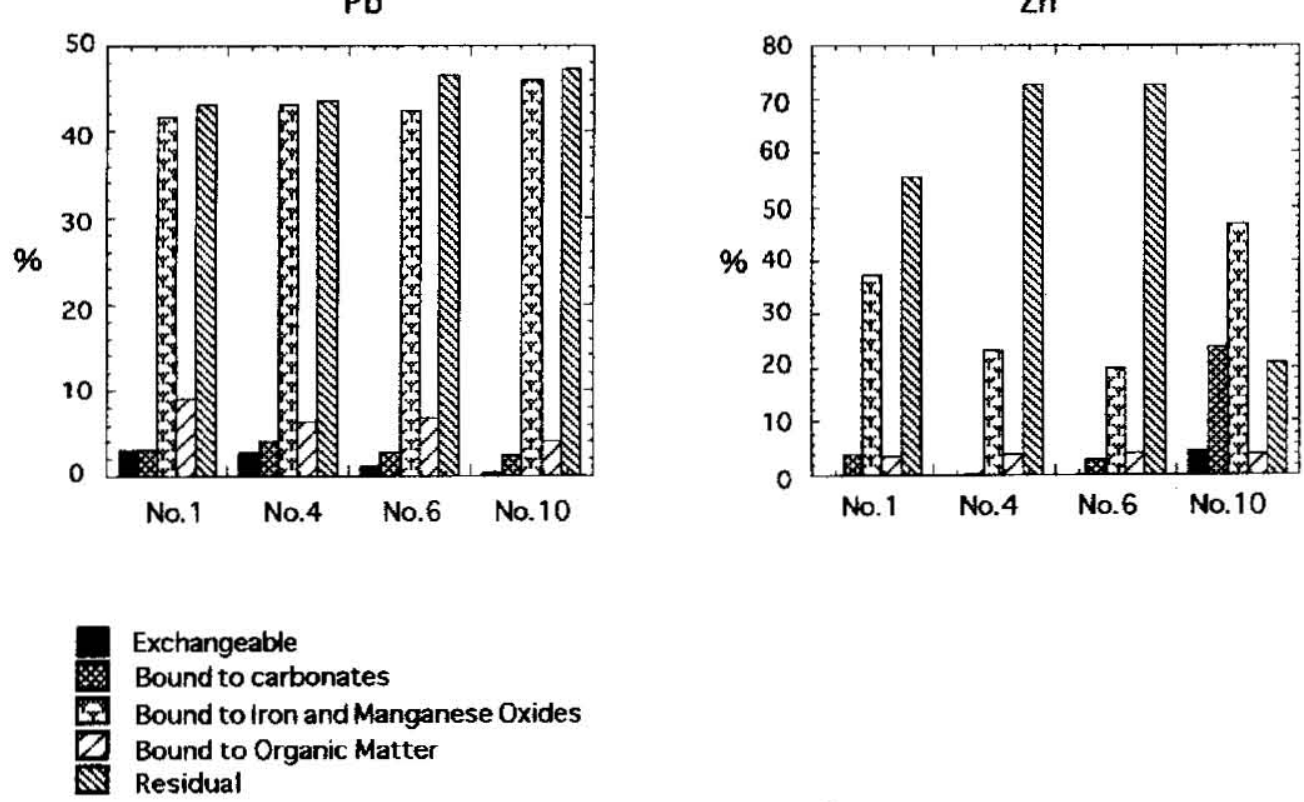

Fig. 3. Percentages of $\mathrm{Cu}, \mathrm{Ni}, \mathrm{Pb}$, and $\mathrm{Zn}$ associated with each of five sequential fractions for agricultural soils and river-sediment, in which the content of the residual fraction calculated as the difference between the total content and the total of the contents of four fractions excluding the residual fraction was used as such. 
the measurement of the residual fraction and the total content. In this context, the content of the residual fraction was calculated as the difference between the total contents listed in Table 2 and the total of the contents of four fractions excluding the residual fraction and is shown in the parenthesis of Table 3.

Percentages of heavy metals associated with each of five sequential fractions for agricultural soils and river-sediment were calculated using two values for the residual fraction, and are illustrated in Figs. 2 and 3. Percentages of each fraction were different between the two figures, but general tendency was found to be similar to each other.

\section{a) Copper}

Among the agricultural soils, samples No.4 and No.6 showed the highest proportion of the residual fraction, occupying $50-63$ and $67-80 \%$ of the total, respectively. The Fe-Mn oxides and organic fractions followed the residual fraction and showed the similar percentage to each other. The exchangeable fraction was not detected and the carbonates fraction accounted for not detected to $0.4-0.6 \%$. In comparison to samples No.4 and No.6, sample No.1 which is possibly polluted with Cu showed the significantly high proportion of the $\mathrm{Fe}-\mathrm{Mn}$ oxides fraction. The exchangeable fraction was not detected and the carbonates fraction accounted for 1.9-2.6\%. Copper added to soil may quickly move to the Fe-Mn oxides fraction and slowly change to the residual fraction.

The river-sediment collected from the Kimngum River showed the quite high proportion of the fraction associated with organic matter. The organic fraction was in $64-78 \%$. The high proportion of the organic fraction can be partially ascribed to the high organic matter content of the river-sediment (Ho and Egashira, 1999). In addition, organic compounds under the reduced condition may be more active to bind with $\mathrm{Cu}$. According to Tessier et al. (1980) Cu exhibited the highest stability constants for the most ligands of all the metals considered. The high affinity of organic ligands makes $\mathrm{Cu}$ more stable in the river bed, leading to the suppression of diffusion or dispersion of $\mathrm{Cu}$.

\section{b) Lead}

Distribution of $\mathrm{Pb}$ in the agricultural soils and river-sediment followed entirely the same order: $\mathrm{Fe}-\mathrm{Mn}$ oxides $\geq$ residual $>$ organic $>$ carbonates $>$ exchangeable. The fraction of $\mathrm{Fe}-\mathrm{Mn}$ oxides occupied about $40-60 \%$ of the total $\mathrm{Pb}$. The highest proportion of the Fe-Mn oxides fraction was reported by Tessier et al. (1980), Ramos et al. (1994) and Ma and Rao (1997) for soils and sediments highly concentrated or polluted with heavy metals, although the percentage of the $\mathrm{Fe}-\mathrm{Mn}$ oxides fraction and the sequence following the $\mathrm{Fe}-\mathrm{Mn}$ oxides fraction varied with soils and sediments. Lead added to soil or sediment may react selectively with Fe-Mn oxides and quickly move to the stable form. The sum of the exchangeable and carbonates fractions only represented 3-4 to 7-9\% of the total $\mathrm{Pb}$, and rather lower for the river-sediment. Association of $\mathrm{Pb}$ with $\mathrm{Fe}-\mathrm{Mn}$ oxides in the river-sediment may prevent $\mathrm{Pb}$ from diffusion or dispersion to environment.

\section{c) Nickel}

Speciation of Ni was different between agricultural soils and river-sediment. The order was residual $>$ Fe-Mn oxides $>$ organic $>$ carbonates, exchangeable for the agricultural soils and Fe-Mn oxides $>$ carbonates $>$ organic, exchangeable, with variation of residual, for the river-sediment.

The residual fraction accounted for 44-46 to $55-64 \%$ of the total Ni for agricultural soils while $10-24 \%$ for river-sediment, although 'Tessier et al. (1980) and Hickey and 
Kittrick (1984) reported that majority of $\mathrm{Ni}$ in soils and sediments highly concentrated or polluted with heavy motals was in the residual fraction. The exchangeable and carbonates fractions were $8-9$ and $14-17 \%$, respectively, for the river-sediment. The higher proportion of the easily extractable forms of $\mathrm{Ni}$ is a characteristic of the river-sediment. Continuous addition of the river-sediment to agricultural field may become a source of $\mathrm{Ni}$ pollution to crops growing on the field.

\section{d) Zinc}

Because of a close relationship between Zn and Ni (Ho and Egashira, 1999), speciation of $\mathrm{Zn}$ was similar to that of $\mathrm{Ni}$ and clcarly different between agricultural soils and river-sediment. Zinc in each fraction generally followed the following order: residual $>\mathrm{Fe}-\mathrm{Mn}$ oxides $>$ organic $>$ carbonates $>$ exchangeable for the agricultural soils; Fe-Mn oxides $>$ carbonates $>$ exchangeable, organic, with variation of residual, for the river-sediment. Although there was considerable variation with soils in the proportion to the total $\mathrm{Zn}$ in various fractions, $\mathrm{Zn}$ was primarily in the residual or Fe-Mn oxides fraction in agricultural soils.

In the river-sediment, the highest proportion was obtained in the $\mathrm{Fe}-\mathrm{Mn}$ oxides fraction, with the residual fraction being 4-21\%. Tessier et al. (1980), Kuo et al. (1983) and Hickey and Kittrick (1984) showed that $\mathrm{Zn}$ was primarily associated with $\mathrm{Fe}-\mathrm{Mn}$ oxides in soils and sediments highly concentrated or polluted with heavy metals. The exchangeable fraction was essentially not detected in agricultural soils but 4-5\% for river-sediment. The carbonales fraction was $0.3-0.5$ to $4-5 \%$ and $24-29 \%$ for agricultural soils and rive-sediment, respectively. The sum of the exchangeable and carbonate fractions amounted to as high as $28-34 \%$ for the river-sediment. The relatively high proportion of the easily extractable forms suggests the high mobility of $\mathrm{Zn}$ and a possible source of the river-sediment as Zn pollution to crops.

\section{DISCUSSION}

From the viewpoint of assessment to the emvironmental impact of soils and sediments polluted with heavy metals, speciation of heavy metal as well as its total content is necessary. Total contents of different heavy metals of the agricultural soils and river-scdiment taken from Tuliem and Thanhtri districts of Hanoi city was assessed in the previous paper (Ho and Egashira, 1999). In the present study, speciation of $\mathrm{Cu}, \mathrm{Ni}, \mathrm{Pb}$, and $\mathrm{Zn}$ was assessed by the sequential extraction with distribution into five fractions: exchangeable, bound to carbonates, bound to $\mathrm{Fe}-\mathrm{Mr}$ oxides, bound to organic matter, and residual. In agricultural soils with a normal range of the total heavy metal contents, the highest proportion was observed in the residual or Fe-Mn oxides fraction, depending on the heavy metals. This indicates the intimate association of heavy metals with clay particles or Fe-Mn oxides, suggesting the existence of heavy metals as the stable form in agricultural soils, and is comparable with the significant and positive correlations between total metal content and clay and/or free $\mathrm{Fe}_{2} \mathrm{O}_{3}$ contents observed for several heavy metals in the previous study (Ho and Egashira, 1999). The organic fraction was in the third position, ranging from 4 to $24 \%$. The carbonates fraction was less than $5 \%$ and the exchangeable fraction was essentially not detected. Initially adsorbed heavy metals are retained in the exchangeable form and may pass into more specific and stable forms with 
time (Becketı, 1989).

In the river-sediment which was highly accumulated with different heavy metals, speciation of heavy metals was different from that of the agricultural soils and varied with heavy metals (Figs. 2 and 3 ). In case of $\mathrm{Cu}$, the highest fraction was the organic fraction with a percentage of around $70 \%$. The content of $\mathrm{Cu}$ extracted as the organic fraction was higher by about $20-40$ times for the river-sediment than for the agricultural soils, but the content of $\mathrm{Cu}$ extracted as the residual fraction was the same between them (Table 3). This suggests that $\mathrm{Cu}$ added to the river as industrial discharge was deposited and preferentially reacted with organic compounds, due to the high affinity of $\mathrm{Cu}$ to organic ligands, in the river-sediment. Vcry small portions of Cu added existed as the exchangeable, carbonates or $\mathrm{Fe}-\mathrm{Mn}$ oxides form. Distribulion of $\mathrm{Pb}$ into the five fractions was essentially the same between agricultural soils and river-sediment (Figs. 2 and 3 ). The contents of each fraction, except for the exchangeable fraction, of the river-sediment was higher by 2-4 times than those of the agricultural soils (Table 3), indicating that $\mathrm{l}$ b added as industrial discharge was distributed in a fixed proportion into different fractions. This suggests that $\mathrm{Pb}$ has the highest affinity to solid particles in soils and sediments and quickly move to the ultimate distribution.

Distribution of $\mathrm{Ni}$ and $\mathrm{Zn}$ in the river-sediment was similar to cach other and clearly different from that of the agricuitural soils. In agricultural soils the proportion of the residual fraction was highest followed by the Fe-Mn oxides fraction, whereas in the river-sediment the proportion of the Fe-Mn oxides fraction was highest followed by the carbonates fraction, and the residual fraction was 10-24 and 4-21\% for $\mathrm{Ni}$ and $\mathrm{Zn}$, respectively (Figs. 2 and 3 ). The contents of both metals in the sequentially-fractionated residual fraction in the river-sediment were equal to or cven below those in the agricultural soils (Table 3). The contents of the other four factions were always higher for the river-sediment than for the agricultural soils. Among the four fractions, increasing rate was extraordinarily high for the exchangeable and carbonates fractions. This indicates that considerable parts of $\mathrm{Ni}$ and $\mathrm{Zn}$ added as industrial discharge exist in the easily extractable and more mobile forms in the river-sediment. From this viewpoint, Ni and $Z_{n}$ are more probable pollutants to agricultural soils and water. Its higher mobility along with the highest content in the river-sediment (Table 2) suggests that the first priority should be placed on the control of $\mathrm{Zn}$ in the industrialized and densely-populated area of Tuliem and Thanhtri districts in Hanoi city.

\section{CONCLLSIONS}

Speciation or distribution into different fractions of $\mathrm{Cu}, \mathrm{Ni}$, and $\mathrm{Zn}$ in the river-sediment which was highly concentrated or polluted with various heavy metals was different from that of agricultural soils having a normal range of the total heavy metal contents. Copper was mostly associated with the organic fraction but considerable parts of $\mathrm{Ni}$ and $\mathrm{Zn}$ existed in the exchangeable and carbonates fractions. Based on the higher mobility and the high total content, $\mathrm{Zn}$ is the most serious pollutant to agricultural soils and water in Tuliem and Thanhtri districts of Hanoi city. 


\section{REFERENCES}

Beckett. P. H. T, 1989 The use of extractants in studies on trace metals in soils, sewage sludges, and sluge-treated soils. Adnum Soil Sit, 9: 143-176

Hickey, M. G. and J. A. Kittrick 1984 Chemical partitioning of cadmium, copper, nickel and zinc in soils and sediments containing high levels of heavy metals. J. Fnviron Qual, 13: 372-376

Ho Thi Lam Tra and K. Egashira 10og Heavy motal status of agricultural soils in Tuliom and Thanhtri districts of Hanoi city, Vietnam. J. Fac. Agr, Kyushu Univ, 43: in press

Kuo, S., P. E. Heilman and A. S. Baker 1983 Distribution and forms of copper, zinc, cadmiurn, iron, and manganesc in soils near a copper smelter. Soil Sci., 135: 101-109

Ma, I. Q. and G. N. Rao 1997 Effects of phosphate rock on sequential chemical extraction of lead in contaminated solls. J. Environ. Qual., 26: $788-794$

Ramos, L., L. M. Hernandez and M. J. Gonzalez 1994 Sequential fractionation of copper, lead, cadmium and zinc in soils from near Donana National Park. J. Environ. Qual, 23: $50-57$

Tessier, A., P. G. C. Campbell and M. Bisson 1979 Sequential extraction procedure for the speciation of particulate trace metals. Anal. Chem, $\mathbf{5 1}: 844-851$

Tessier, A., P. G. C. Campbel and M. Bisson 1980 Trace metal speciation in Yaniaska and St. Francois rivers (Quebec). Can. J. Earth Sci., 17:90.105 